\title{
NOTES
}

\section{Preparation and Thermal Properties of Poly(enaryloxynitrile)s}

\author{
Hyun-Seok Moon, Jin-Seok Kim, Chang Bae KIM, \\ and Myoung Seon GoNG \\ Department of Chemistry, Dankook University, \\ Cheonan 330-714, Chungnam, Korea
}

(Received April 22, 1992)

\begin{abstract}
KEY WORDS Dicyanovinyl Compound / Poly(enaryloxynitrile)s / Aromatic Diols / Thermal Stable Polymer / Heat Curable Polymer /
\end{abstract}

Amines as a nucleophile can readily replace the chlorine of dicyanovinyl compounds, 1chloro-1-phenyl-2,2-dicyanoethene (1) and $p$ bis(1-chloro-2,2-dicyanovinyl)benzene (2) to form enaminonitriles. ${ }^{1}$

Moore and coworkers first synthesized poly(enaminonitrile)s based on the reaction of difunctional dicyanovinyl compound, 2 with aromatic $^{2-4}$ or aliphatic diamines. ${ }^{5}$ Aromatic diamines underwent solution polymerization in aprotic polar solvent in the presence of acid acceptor, whereas aliphatic diamines underwent interfacial polymerization. ${ }^{5,6}$ The resulting polymers showed a good thermal stability and insolubility in the solvent for the untreated polymer, after heat curing without evolution of small molecules. These flexible polymeric precursor which cyclizes to produce the final thermal stable, rigid rod polymer have been compared with polyimides as a thin film without void and contraction caused by emission of volatile product.

The more strongly nucleophlic phenoxide anion possessing a $\mathrm{p} K_{\mathrm{a}}$ value of 10 has an appreciable reactivity to $\mathbf{2}$. Recently, it has been reported that poly(enaryloxynitrile)s prepared from 2 and disodium salts of bisphenol-A showed excellent thermal stability. ${ }^{7}$

In the present paper, we report details of a successful synthesis of a new class of thermal curable poly(enaryloxynitrile)s derived from 2 and aromatic diols such as catechol, resorcinol, hydroquinone and various dihydroxynaphthalenes. In addition, thermal properties of poly(enaryloxynitrile)s are investigated and presented.

\section{EXPERIMENTAL}

1-Chloro-1-phenyl-2,2-dicyanoethene (1) and monomer (2) were synthesized by the modified method previously reported by Moore et $a l .{ }^{4}$ Catechol, resorcinol, hydroquinone and dihydroxynaphthalene derivatives were perchased from Aldrich Chemical Co. and used without further purification.

The IR spectra were obtained with a Perkin-Elmer Model 1310 spectrophotometer and ${ }^{1} \mathrm{H}$ and ${ }^{13} \mathrm{C}$ NMR spectra were recorded on a Bruker Am-300 spectrometer. GPC data were obtained by Waters HPLC using three columns ( $\mu$-styragel $10^{2}, 10^{3}$, and $10^{4} \AA$ ) in $\mathrm{THF}$ at $25^{\circ} \mathrm{C}$, and polystyrene standards were used for calibration. Elemental analyses data were obtained with a Yanaco MT-3, CHNAnalyzer. Thermal analyses were performed with a Dupont 910 and 961 thermal analyzer. 
Preparation of p-Bis(1-phenyl-2,2-dicyanoviniyloxy)benzene

$0.55 \mathrm{~g}(5.0 \mathrm{mmol})$ of hydroquinone was dissolved in the solution of $0.23 \mathrm{~g}(5.8 \mathrm{mmol})$ of sodium hydroxide in $20 \mathrm{ml}$ of water with gentle swirling for 4 hours and the reation mixture was transferred to the blender. A mixture of $1.89 \mathrm{~g}(10 \mathrm{mmol})$ of 1 in $20 \mathrm{ml}$ of 1,2-dichloroethane was poured in one portion into the blender. After the blender was stirred at full speed for 2 minutes, the organic layer was separated and the solvent was evaporated. The greenish solid product was filtered and recrystallized from acetone.

A similar procedure was applied to the synthesis of model compound $\mathbf{4}$ by reaction two equivalents of sodium $\beta$-naphthoxide with 2.

3. Yield $90 \%$; $\mathrm{mp} 282^{\circ} \mathrm{C}$.

IR (KBr): 3050, 2250, 1590, 1500, 1330, and $1180 \mathrm{~cm}^{-1}$.

${ }^{1} \mathrm{H}$ NMR $\left(\mathrm{CDCl}_{3}\right): \delta=7.3-7.7(\mathrm{~m}, 10 \mathrm{H}$, aromatic H's in 1), and $7.0-6.8 \mathrm{ppm}(\mathrm{m}, 4 \mathrm{H}$, aromatic H's in hydroquinone).

${ }^{13} \mathrm{C}$ NMR: $\delta=71.9 \quad\left(=\underline{\mathrm{C}}(\mathrm{CN})_{2}\right), \quad 110.5$, $113.5(-\mathrm{CN}), 122.5,128.0,129.2,130.0,132.8$, 151.5 (aromatic C's), and $180.5 \mathrm{ppm}(=\underline{\mathrm{C}}-\mathrm{O}-)$.

Anal. Calcd: C, $77.2 \% ; \mathrm{H}, 1.0 \% ; \mathrm{N}, 13.9 \%$, Found: $\mathrm{C}, 76.8 \% ; \mathrm{H}, 1.0 \%$; N, $14 \%$.

4. Yield $87 \% ; \mathrm{mp} 302-304^{\circ} \mathrm{C}$.

IR (KBr): 3040, 2220, 1595, 1327, and 1165 $\mathrm{cm}^{-1}$.

${ }^{1} \mathrm{H}$ NMR $\left(\mathrm{CDCl}_{3}\right): \delta=7.3-7.7 \quad(\mathrm{~s}, 4 \mathrm{H}$, aromatic H's in fragment of 2), and 6.8-7.2 ppm (m, 14H, naphthyl H's).

${ }^{13} \mathrm{C}$ NMR $\left(\mathrm{CDCl}_{3}\right): \delta=71.0\left(=\underline{\mathrm{C}}(\mathrm{CN})_{2}\right)$, $111.5,112.9(-\mathrm{CN}), 12.9,127.4,128.7,129.6$, $133.1,151.2$ (aromatic C's), and $181.0 \mathrm{ppm}$ (= $\underline{\mathrm{C}}-\mathrm{O}-$ ).

Anal. Calcd: C, $79.4 \% ; \mathrm{H}, 3.5 \% ; \mathrm{N}, 10.9 \%$, Found: C, $79.1 \% ; \mathrm{H}, 3.6 \%$;, $10.7 \%$.

Representative Polymerization of $\mathbf{2}$ with Disodium Salts of Aromatic Diol in Homogeneous Solution

A solution of $0.99 \mathrm{~g}(9.0 \mathrm{mmol})$ of hydro- quinone and $0.72 \mathrm{~g}(18.0 \mathrm{mmol})$ of powdered sodium hydroxide in $20 \mathrm{ml}$ of dimethylformamide was stirred with nitrogen inlet for 8 hours $2.69 \mathrm{~g}(9.0 \mathrm{mmol})$ of 2 in $10 \mathrm{ml}$ of dimethylformamide was added and the temperature was raised to $50^{\circ} \mathrm{C}$ and maintained for 2 hours. The pale yellow solution was allowed to cool and was poured into a large amount of water to precipitate the polymer $\mathbf{5}$.

A similar polymerization procedures were applied to prepare other polymers.

Representative Polymerization of $\mathbf{2}$ with Disodium Salts of Aromatic Diol by Interfacial Techniques

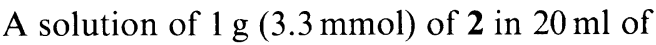
1,2-dichloroethane was transferred to the blender. A hydroquinone $(0.36 \mathrm{~g}, 3.3 \mathrm{mmol})$ in $20 \mathrm{ml}$ of water was added to the blender at full speed for 2 minutes. The polymer was collected and washed with water. The polymer was dried at $60^{\circ} \mathrm{C}$ under vacuum for 5 hours.

A similar procedures were applied to prepare other polymers. In the case of dihydroxynaphthalene-derived polymers, nitrobenzene was used as a organic solvent in place of 1,2-dichloroethane.

7. Yield $95 \%$.

IR (KBr): 3010, 2820, 2220, 1595, 1490, 1400, 1310 , and $1210 \mathrm{~cm}^{-1}$.

${ }^{1} \mathrm{H}$ NMR $\left(\mathrm{CD}_{3} \mathrm{CN}\right): \delta=7.3-7.6(\mathrm{~m}, 4 \mathrm{H}$ aromatic H's in fragment in 2), and 6.5-6.9 ppm (m, aromatic H's in Hydroquinone).

${ }^{13} \mathrm{C} \quad \mathrm{NMR}: \quad \delta=72.0 \quad\left(=\mathrm{C}(\mathrm{CN})_{2}\right), \quad 110.1$, $113.8,(-\underline{\mathrm{C}}), 121.8,128.0,128.9,129.3,133.4$, $134.1,152.1$ (aromatic C's), and $180.1 \mathrm{ppm}$ (= $\mathrm{C}-\mathrm{O}-$ ).

Anal. Calcd: C, $71.4 \% ; \mathrm{H}, 2.4 \% ; \mathrm{N}, 16.7 \%$, Found: C, $71.7 \% ; \mathrm{H}, 2.5 \% ; \mathrm{N}, 16.5 \%$.

12. Yield $92 \%$.

IR (KBr): 3040, 2210, 1600, 1510, 1330, 1250, and $1160 \mathrm{~cm}^{-1}$.

${ }^{1} \mathrm{H}$ NMR (DMSO- $\left.d_{6}\right): \delta=7.2-7.6(\mathrm{~s}, 4 \mathrm{H}$, aromatic H's in fragment in 2), and 7.3-6.6 ppm $(6 \mathrm{H}$, aromatic H's in naphthalene).

${ }^{13} \mathrm{C} \mathrm{NMR}\left(\mathrm{DMSO}-d_{6}\right): \delta=71.3(=\underline{\mathrm{C}}(\mathrm{CN}))_{2}$, 
$110.9,113.0(-\mathrm{CN}), 121.8,126.9,128.6,129.6$, 130.3, 133.0, 151.2 (aromatic C's), and 181.2 $\operatorname{ppm}(=\underline{\mathrm{C}}-\mathrm{O}-)$.

Anal. Calcd: C, $74.6 \% ; \mathrm{H}, 2.6 \% ; \mathrm{N}, 14.5 \%$,

Found: C, $75.0 \% ; \mathrm{H}, 2.7 \% ; \mathrm{N}, 14.7 \%$.

\section{RESULTS AND DISCUSSION}

Two different model compounds, $p$-bis(1phenyl-2,2-dicyanovinyloxy) benzene (3) and $p$-bis[1-( $\beta$-naphthyloxy)-2,2-dicyanovinyl]benzene (4) were prepared by reacting the aryloxide anion derived from hydroquinone and $\beta$-naphthol with dicyanovinyl compounds, 1 and 2.

The model products, 3 and $\mathbf{4}$ were identified to be enaryloxynitrile by IR, ${ }^{1} \mathrm{H}$ and ${ }^{13} \mathrm{C}$ NMR spectroscopy and characterized by satisfactory elemental analysis.

The polymerization of $\mathbf{2}$ with disodium salts of aromatic diols could proceed by both solution and interfacial polymerization techniques.

Aromatic diols such as catechol, resorcinol,<smiles>[Y][CH-][CH+]</smiles>

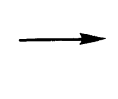<smiles>N#CC(C#N)=C(Oc1ccc(OC(=C(C#N)C#N)c2ccccc2)cc1)c1ccccc1</smiles>

$\underline{3}$<smiles>Cc1ccc2ccccc2c1</smiles><smiles>N#CC(C#N)=C(Oc1ccc2ccccc2c1)c1ccc(C(Oc2ccc3ccccc3c2)=C(C#N)C#N)cc1</smiles>

$\underline{4}$

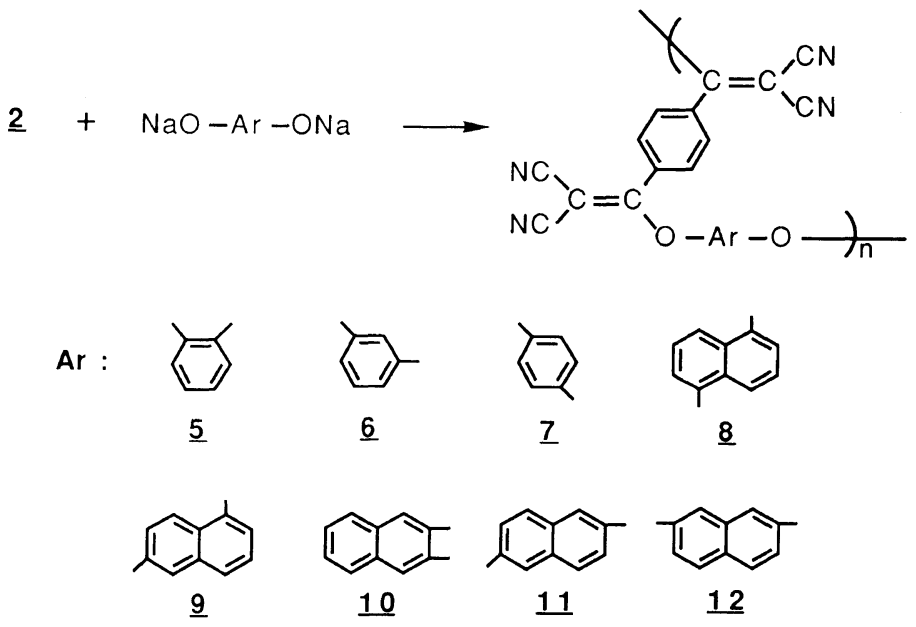


H-S. MoON et al.

Table I. Polymerization results of $\mathbf{2}$ and disodium salts of aromatic diols

\begin{tabular}{|c|c|c|c|c|c|c|c|c|}
\hline Polymer & $\operatorname{Diol}^{c}$ & Solvent & Temp $/{ }^{\circ} \mathrm{C}$ & Time/min & Yield/\% & $\eta_{\mathrm{inh}}{ }^{\mathrm{d}}$ & $M_{n}{ }^{\mathrm{e}}$ & $M_{w}$ \\
\hline $5^{\mathrm{a}}$ & $\mathrm{Ca}$ & $\mathrm{C}_{2} \mathrm{H}_{4} \mathrm{Cl}_{2} / \mathrm{H}_{2} \mathrm{O}$ & 25 & 2 & 90 & 0.28 & 5160 & 12400 \\
\hline $5^{b}$ & $\mathrm{Ca}$ & $\mathrm{DMF}$ & 50 & 300 & 93 & 0.30 & 3880 & 13500 \\
\hline $6^{\mathrm{a}}$ & $\mathrm{Re}$ & $\mathrm{C}_{2} \mathrm{H}_{4} \mathrm{Cl}_{2} / \mathrm{H}_{2} \mathrm{O}$ & 25 & 2 & 92 & 0.32 & 6220 & 15500 \\
\hline $7^{\mathrm{a}}$ & Hy & $\mathrm{C}_{2} \mathrm{H}_{4} \mathrm{Cl}_{2} / \mathrm{H}_{2} \mathrm{O}$ & 25 & 2 & 95 & 0.31 & 5440 & 15000 \\
\hline $7^{b}$ & Hy & DMF & 50 & 300 & 92 & 0.27 & 4820 & 13800 \\
\hline $8^{\mathrm{a}}$ & $1,5-\mathrm{DhNa}$ & Nitrobenzene $/ \mathrm{H}_{2} \mathrm{O}$ & 20 & 2 & 85 & 0.10 & 4780 & 11240 \\
\hline $9^{a}$ & $1,6-\mathrm{DhNa}$ & Nitrobenzene $/ \mathrm{H}_{2} \mathrm{O}$ & 20 & 2 & 89 & 0.17 & 5700 & 12000 \\
\hline $10^{\mathrm{a}}$ & 2,3-DhNa & Nitrobenzene $/ \mathrm{H}_{2} \mathrm{O}$ & 20 & 2 & 87 & 0.12 & 4800 & 12440 \\
\hline $11^{\mathrm{a}}$ & 2,6-DhNa & Nitrobenzene $/ \mathrm{H}_{2} \mathrm{O}$ & 20 & 2 & 92 & 0.16 & 4540 & 11200 \\
\hline $12^{\mathrm{a}}$ & 2,7-DhNa & Nitrobenzene $/ \mathrm{H}_{2} \mathrm{O}$ & 20 & 2 & 91 & 0.21 & 6100 & 11500 \\
\hline $12^{b}$ & $2,7-\mathrm{DhNa}$ & DMF & 60 & 300 & 89 & 0.28 & 4200 & 13200 \\
\hline
\end{tabular}

a Interfatial polymerization.

b Solution polymerization.

c $\mathrm{Ca}$, catechol; Re, resorcinol; Hy, hydroquinone; DhNa, dihydroxynaphthalene.

${ }^{d}$ Measured at a concentration of $1 \mathrm{~g} \mathrm{dl}^{-1}$ in $N$-methyl-2-pyrrolridinone at $25^{\circ} \mathrm{C}$.

e $M_{\mathrm{n}}$ and $M_{w}$ of polymers, which is partially soluble in acetonitrile, were obtained by using three columns ( $\mu$-styragel $10^{2}, 10^{3}$, and $10^{4} \AA$ ) in THF at $25^{\circ} \mathrm{C}$, and polystyrene standards were used for calibration.

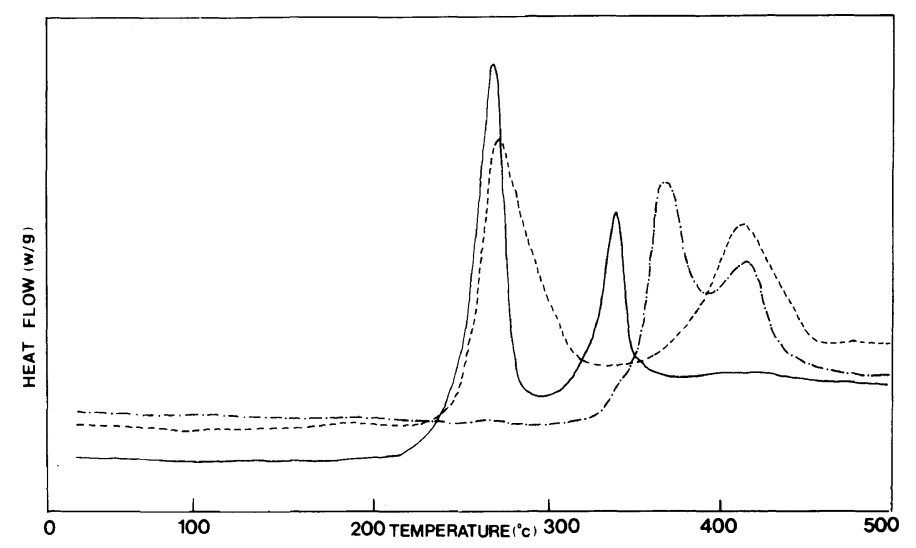

Figure 1. DSC thermogram of polymers from catechol (-), resorcinol (-----), and hydroquinone $(-\cdot \cdot-)$ with $p$-bis(1-chloro-2,2-dicyanovinyl)benzene.

hydroquinone and various dihydroxynaphthalene derivatives were selected and their disodium salts were readily polymerized with $\mathbf{2}$ to give the corresponding polymers 5-12 in high conversion. The polymerization results are summarized in Table I.

When polymer $\mathbf{7}$ and $\mathbf{1 2}$ were compared with the model compound $\mathbf{3}$ and $\mathbf{4}$, respectively, the spectral data of polymers matched well with those of the model compounds.

In the case of polymer 7 , the ${ }^{1} \mathrm{H}$ NMR peaks of the aromatic protons in hydroquinone are shown as a multiplet at $6.5-6.9 \mathrm{ppm}$, whereas those of 2 unit are seen as a broad singlet between 7.3-7.6 ppm. The characteristic bands of poly(enaryloxynitrile) in its IR spectra are exhibited at 2220, 1595, and $1160-1210 \mathrm{~cm}^{-1}$ corresponding to $\mathrm{C} \equiv \mathrm{N}, \mathrm{C}=\mathrm{C}$, and $\mathrm{C}-\mathrm{O}$ 
bands, respectively. The proposed structures of polymer were also comfirmed by ${ }^{13} \mathrm{C}$ NMR spectra. The peak at $180.5 \mathrm{ppm}$ indicated the presence of the enaryloxy linkage $(=\underline{\mathrm{C}}-\mathrm{O}-)$ apparently.

Polymers 8-12 derived from dihydroxynaphthalene were also identified as poly(enaryloxynitrile) by comparison with their IR,
${ }^{1} \mathrm{H}$ and ${ }^{13} \mathrm{C}$ NMR spectra with different kind of model compound 4.

All the polymers were soluble in polar aprotic solvents such as DMF, DMSO, DMAc, and $N$-methyl-2-pyrrolidinone, and partially soluble in acetonitrile, nitrobenzene and THF. Polymers 8 - 12 were less soluble than polymers $5-7$ in such solvent.

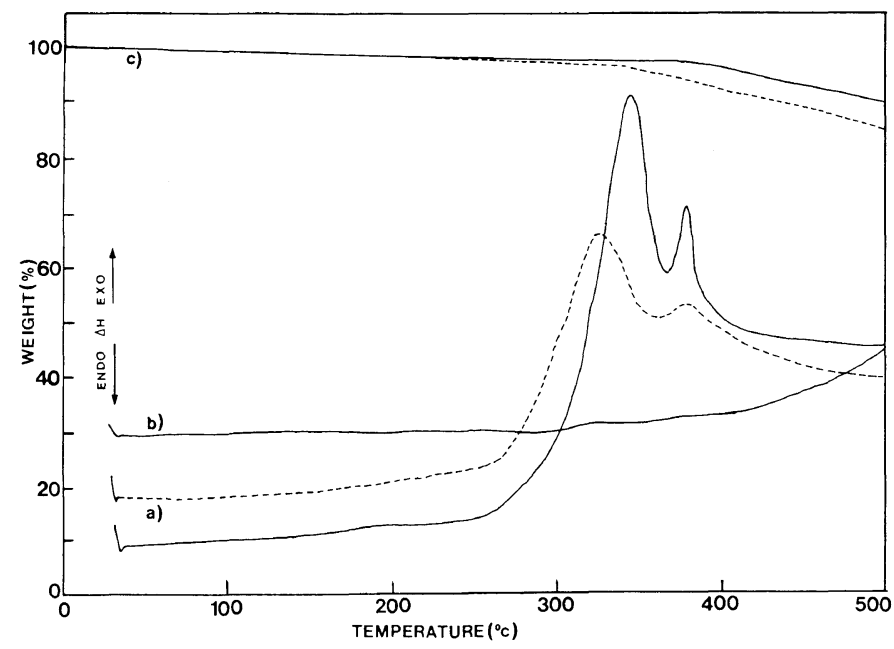

Figure 2. DSC thermogram of (a) 1st heating, (b) 2nd heating, and (c) TGA thermogram of polymers obtained from 1,6-dihydroxy naphthalene (-----) and 2,7-dihydroxy naphthalene (- $\longrightarrow$ with p-bis(1-chloro-2,2-dicyanovinyl)benzene.

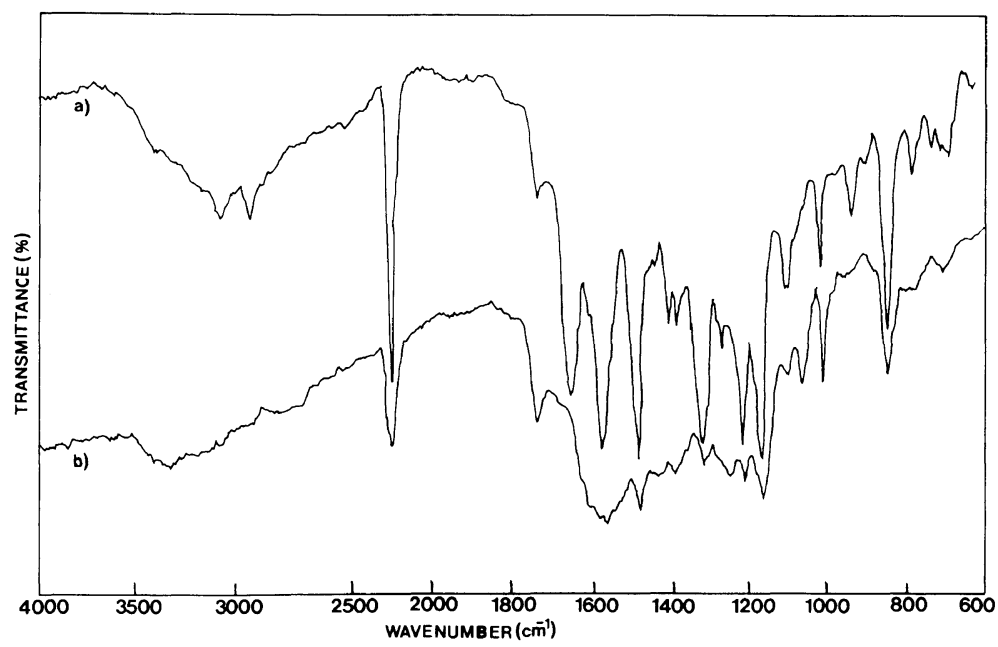

Figure 3. Infrared spectra poly(enaryloxynitrile) from disodium salts of hydroquinone and $p$-bis(1-chloro-2,2-dicyanovinyl)benzene after (a) $0 \mathrm{~h}$ and (b) $1.5 \mathrm{~h}$ at $350^{\circ} \mathrm{C}$ under nitrogen. 
The polymers of soluble portion in acetonitrile, 5-7 appeared to possess molecular weight of $M_{n}=4000-6000$ and $M_{w}=12000$ 15000. However, these are not high molecular weight judging from viscosity and GPC data, but the clear and hard films were cast from the N-MP solution on a glass. Films of these polymers adhered very strongly to glass surfaces. Poly(ennaphthyloxynitrile)s, 8-12 exhibited lower molecular weight than corresponding polymer 5-7. These polymers with inherent viscosity of more than 0.1 could be cast from DMF into transparent films but were somewhat brittle and fingernail-creasable.

As can be seen from Figures 1 and 2(a), all the polymers show interesting differential scanning calorimetry (DSC) curves with two consecutive large exotherms. The calorigrams of these polymers did not show any traces of glass transition temperature.

The first exothermic peak appears at 272, 274 , and $363^{\circ} \mathrm{C}$ for polymers 5,6 , and 7 , respectively. In the case of poly(ennaphthyloxynitrile)s incorporating naphthalene unit, the temperatures of first exotherm are between 320 and $350^{\circ} \mathrm{C}$, and second exotherm peak is smaller and $40^{\circ} \mathrm{C}-50^{\circ} \mathrm{C}$ higher than the first exotherm. They disappear upon cooling and rescanning the samples as illustrated in Figure 2(b). After these polymers have been heated

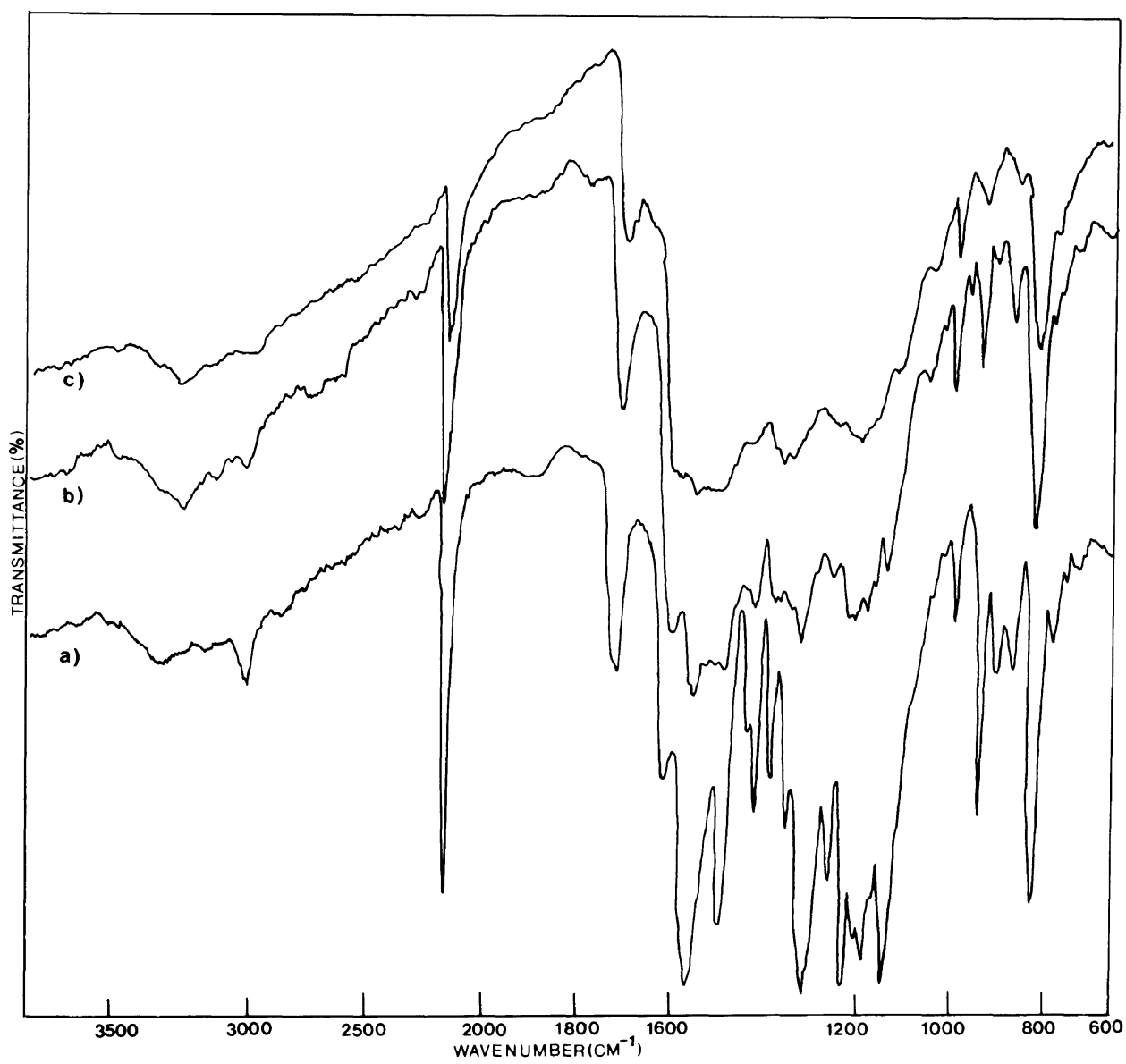

Figure 4. Infrared spectra of poly(enaryloxynitrile) derived from disodium salts of 2,7-dihydroxy naphthalene and $p$-bis(1-chloro-2,3-dicyanovinyl)benzene after (a) $0 \mathrm{~h}$, (b) $1 \mathrm{~h}$, and (c) $2 \mathrm{~h}$ at $350^{\circ} \mathrm{C}$ under nitrogen. 


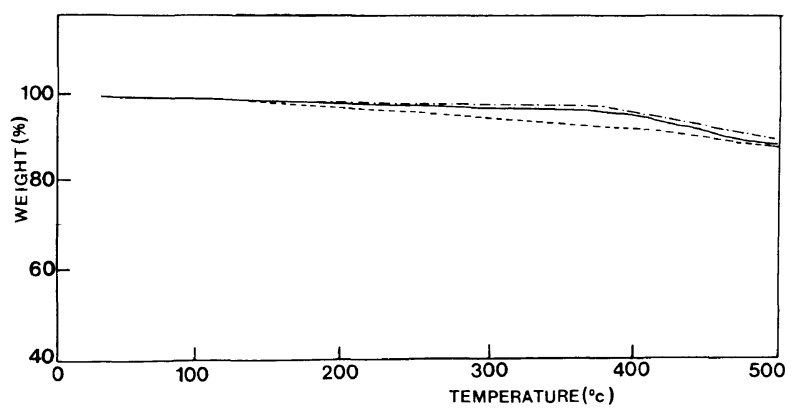

Figure 5. TGA thermogram of polymers obtained from cathecol (-----), resorcinol ( -$)$, and hydroquinone (-.--) with $p$-bis(1-chloro-2,2-dicyanovinyl)benzene with a heating rate of $10^{\circ} \mathrm{Cmin}^{-1}$ in nitrogen atmosphere.

beyond the temperature of first exotherm, solubility of solvent, from which the films were cast, decreased or they were no longer soluble in the solvent for the untreated polymers.

Polymer 7 heated to $320^{\circ} \mathrm{C}$ changed color from yellowish green to orange and displayed a gradual change in their IR spectra as they were heated. The nitrile band at $2220 \mathrm{~cm}^{-1}$ decreased apparently and broad strong band between 1700 and $1560 \mathrm{~cm}^{-1}$ attributable to $\mathrm{C}=\mathrm{C}$ or $\mathrm{C}=\mathrm{N}$ double bond appeared as shown in Figure 3.

For the polymers 8 -12, the nitrile stretching band was also reduced after curing over 2 hours at $350^{\circ} \mathrm{C}$, while the absorption bands at $1650-1580 \mathrm{~cm}^{-1}$ appeared (Figure 4).

Besides the phenomena mentioned above, a slight loss of weight in their TGA curves at corresponding temperature also indicated that the structure of polymer changed without decomposition or evolution of small molecules. It might be happened that rearrangement or cross-linking of the dicyanovinyl group occurred during heating at the temperature of its first exotherm. It is difficult to confirm at this point the curing mechanism causing this exotherm.

All the polymers show excellent thermal stability as shown in Figure 2(c) and Figure 5.

Thermogravimetric analysis results are listed in Table II. The polymers 5-7 gave $\mathbf{6 - 7 \%}$ weight loss in nitrogen over a temperature
Table II. Residual weight and thermal properties of poly(enaryloxynitrile)s by DSC and TGA

\begin{tabular}{|c|c|c|c|c|c|}
\hline \multirow{2}{*}{ Polymer } & \multicolumn{3}{|c|}{ Residual weight (\%) } & \multirow{2}{*}{$\begin{array}{c}\text { 1st } \\
\text { exotherm/ } \\
{ }^{\circ} \mathrm{C}\end{array}$} & \multirow{2}{*}{$\begin{array}{c}\text { 2nd } \\
\text { exotherm/ } \\
{ }^{\circ} \mathrm{C}\end{array}$} \\
\hline & $300^{\circ} \mathrm{C}$ & $400^{\circ} \mathrm{C}$ & $500^{\circ} \mathrm{C}$ & & \\
\hline & 94.5 & 93.3 & 88.3 & 272 & 340 \\
\hline 6 & 94.6 & 93.4 & 89.2 & 274 & 419 \\
\hline 7 & 95.3 & 94.7 & 90.0 & 364 & 421 \\
\hline 8 & 93.7 & 89.9 & 80.4 & 347 & $-^{\mathrm{a}}$ \\
\hline 9 & 96.9 & 91.1 & 86.9 & 324 & 380 \\
\hline 10 & 94.7 & 91.3 & 82.2 & 338 & 373 \\
\hline 11 & 92.1 & 88.9 & 80.2 & 334 & 395 \\
\hline 12 & 98.5 & 97.6 & 90.5 & 345 & 378 \\
\hline
\end{tabular}

a Two exothermic temperatures are superimposed around at $350^{\circ} \mathrm{C}$.

range of $400^{\circ} \mathrm{C}$ and $10 \%$ weight at $500^{\circ} \mathrm{C}$. Poly(ennaphthyloxynitrile)s, 8-12 showed $10 \%$ to $20 \%$ weight loss at $500^{\circ} \mathrm{C}$, which were less stable than dihydroxybenzene-derived polymers. In the series of naphthalene-derived polymers, the thermal stability might not be related with the structure of polymer synthesized from various kinds of dihydroxynaphthalenes.

In the experiment of thermal reaction of model compound 3 and $\mathbf{4}$, the chemical process causing such exotherm cannot be elucidated. Further works on the other model compound to investigate the curing mechanism are now in progress. 
Acknowledgement. This paper was supported by NON DIRECTED RESEARCH FUND, Korea Research Foundation, 1991.

\section{REFERENCES}

1. Z. Rappoport and A. Topol, J. Chem. Soc., Perkin Trans. 2, 1823 (1972).

2. J. A. Moore and D. R. Robello, Polym. Prepr., Am. Chem. Soc., Div. Polym. Chem., 27(2), 127 (1986).
3. J. A. Moore and D. R. Robello, Marcromolecules, 19, 2667 (1986).

4. J. A. Moore and D. R. Robello, Marcromolecules, 22, 1084 (1989).

5. J. A. Moore and G. Mehta, Polym. Mater. Sci. Eng., 6, 351 (1990).

6. S. T. Kim, J. O. Lee, Y. S. Kim, and M. S. Gong, Polymer (Korea), 15, 95 (1991).

7. H. S. Moon, S. T. Kim, and M. S. Gong, Makromol. Chem., Rapid Commun., 12, 591 (1991). 